\title{
Characteristics of Young Family Physician Hospitalists
}

\author{
Douglas B. Kamerow, MD, MPH, Peter Wingrove, BA, Stephen Petterson, PhD, \\ Lars Peterson, $M D, P h D$, and Andrew Bazemore, $M D, M P H$
}

Based on a 2016 survey of family physicians who were then three years out of residency training, we found that almost 9 percent self-identified as hospitalists. These family physician hospitalists were significantly more likely than their non-hospitalist peers to be male, work longer hours, be better paid, and be more satisfied with their work. These attributes may attract more family physicians to hospital medicine, with negative implications for the supply of primary care physicians. (J Am Board Fam Med 2018;31:680-681.)

Keywords: Career Choice, Family Physicians, Health Workforce, Hospitalists

The specialty of hospital medicine is now more than 20 years old in the United States. ${ }^{1}$ Most hospitalists are internists and internal medicine subspecialists but a small proportion are family physicians. ${ }^{2}$ We sought to quantify the proportion of young family physicians who are becoming hospitalists and to describe their characteristics, comparing them to young family physicians who are not hospitalists.

We used data from the 2016 Family Medicine National Graduate Survey, which was administered to all board-certified family physicians 3 years after they completed residency in $2013 .{ }^{3}$ The survey instrument included respondent demographics and questions on type of practice, work schedule, income, and work satisfaction. This study was approved by the American Academy of Family Physicians Institutional Review Board. The $\chi^{2}$ and $\mathrm{k}$-sample tests were used to assess statistical significance.

Response rate was $67.8 \%$ of the 3051 doctors surveyed, yielding a sample size of 2069, of whom

This article was externally peer reviewed.

Submitted 01 March 2018; revised 07 May 2018; accepted 21 May 2018.

From Robert Graham Center, Washington, DC (DBK, PW, SP, AB); American Board of Family Medicine, Lexington, KY (LP), University of Pittsburg School of Medicine $(\mathrm{PW})$.

Funding: none.

Conflict of interest: none declared.

Corresponding author: Douglas B. Kamerow, MD, MPH, Robert Graham Center, 1133 Connecticut Ave NW, Suite 1100, Washington, DC 20036 (E-mail: dkamerow@aafp. org).
2034 were in active patient care. Of those in active patient care, $181(8.9 \%)$ of the respondents stated they both did not provide outpatient continuity care and principally self-identified as hospitalists. Men were almost twice as likely as women to be hospitalists $(11.9 \%$ vs $6.6 \%, P<.001)$. On average, hospitalists worked more hours per week than nonhospitalists (64.2 hours vs 53.6 hours, $P<.001$ ). Many more hospitalists than nonhospitalists reported that they worked over 60 hours per week $(46.4 \%$ vs $29.1 \%, P<.001)$. Median income was $\$ 250,000$ for hospitalists versus $\$ 185,000$ for nonhospitalists $(P<$ .001). Hospitalists were more likely to be satisfied or very satisfied with their principal practice overall than their nonhospitalist peers $(92.8 \%$ vs $84.3 \%, P<.01)$. (see Table 1.)

If these findings are generalizable, interest in hospital medicine among family physicians may grow beyond the almost $9 \%$ seen in this survey. Over half of graduating family medicine residents report more than $\$ 150,000$ in educational debt. ${ }^{4}$ The higher compensation of hospitalists might disproportionately attract family medicine graduates with large educational loans to repay. Hospital medicine's fixed hours and lack of on-call responsibilities might also be attractive to graduating residents. If a larger proportion of family physicians become hospitalists, primary care physician shortages might be exacerbated.

We conclude that the respondents in this sample of young family physician hospitalists were signifi- 
Table 1. Comparison of 2016 Survey Responses of 2034 Hospitalist and Nonhospitalist Recently ABFM-Certified Physicians

\begin{tabular}{lccc}
\hline Response & $\begin{array}{c}\text { Hospitalist Family Physicians } \\
\mathrm{N}=181\end{array}$ & $\begin{array}{c}\text { Nonhospitalist Family } \\
\text { Physicians N }=1853\end{array}$ & Significance \\
\hline Satisfied or very satisfied & $92.8 \%(168)$ & $84.3 \%(1563)$ & $P<.01$ \\
Average hrs/wk worked & 64.2 & 53.6 & $P<.001$ \\
Work $>60$ hours/week & $46.4 \%(84)$ & $29.1 \%(539)$ & $P<.001$ \\
Median income & $\$ 250,000$ & $\$ 185,000$ & $P<.001$ \\
Male/Female & $11.9 \%(106 / 889) / 6.6 \%(75 / 1145)$ & - & $P<.001^{*}$ \\
\hline
\end{tabular}

Note: $\mathrm{N}$ denoted by (parentheses).

${ }^{*}$ Comparison is between the proportions of male and female family physicians who are hospitalists.

cantly more likely to be male, work longer hours, be better paid, and be more satisfied with their work than their nonhospitalist peers in family medicine.

To see this article online, please go to: http://jabfm.org/content/ 31/5/680.full.

\section{References}

1. Wachter RM, Goldman L. The emerging role of "hospitalists" in the American health care system. N Engl J Med 1996;335:514-7.
2. Kuo Y-F, Sharma G, Freeman JL, Goodwin JS. Growth in the care of older patients by hospitalists in the United States. N Engl J Med 2009;360:1102-12.

3. Weidner A, Chen F, Peterson L. Developing the National Family Medicine Graduate Survey. J Grad Med Educ 2017;9:570-3.

4. Bazemore A, Peterson L, Jetty A, Wingrove P, Petterson S, Phillips R. Over half of graduating family medicine residents report more than $\$ 150,000$ in educational debt. J Am Board Fam Med 2016;29: $180-1$. 